\title{
Covid-19: European drugs agency to review safety of ibuprofen
}

\author{
Michael Day
}

London

Debate over the safety of non-steroidal anti-inflammatory drugs (NSAIDs) in treating covid-19 has continued with the European Medicines Agency saying that the drugs could be considered for treating the emerging viral illness in some cases.

The agency's comments were prompted by claims from France's health minister Oliver Veran that people showing covid-19 symptoms should use paracetamol rather than ibuprofen, because the latter might worsen the condition. ${ }^{1}$

The minister's comments were themselves prompted by reports in French media that the condition of four young people with covid-19 deteriorated after taking ibuprofen. The hospital mentioned in the reports said that it would not comment on such speculation. This led to comments that the warnings over NSAIDS and covid-19 were based on fake news-despite a raft of experts saying that ibuprofen and other NSAIDs were best avoided by patients with covid-19 given the drugs' safety profile. The EMA has now said: "There is currently no scientific evidence establishing a link between ibuprofen and worsening of covid-19. EMA is monitoring the situation closely and will review any new information that becomes available on this issue in the context of the pandemic."

But it added: "When starting treatment for fever or pain in covid-19, patients and healthcare professionals should consider all available treatment options including paracetamol and NSAIDs. Each medicine has its own benefits and risks which are reflected in its product information."

Paul Little, professor of primary care research at the University of Southampton, who has reviewed the relevant medical literature, told The BMJ that, although there was "no evidence relating specifically to people with covid-19," there was "reasonable evidence of a link between NSAIDs and both respiratory and cardiovascular adverse effects," and therefore caution was the best policy.

"Pending further research, a pragmatic and cautionary approach would be for the public to avoid these plausible harms. Regular NSAID use should probably not be recommended as the first line option for managing the symptoms of covid-19," he said. But he added that patients on low dose aspirin for secondary prevention of cardiovascular disease should be advised to continue, noting that aspirin has anti-inflammatory effects only at much higher doses.

Researchers at the Centre for Evidence-Based Medicine in Oxford have opened up another avenue for debate, however, by questioning the traditional advice of using over-the-counter pills to lower a fever in those with acute respiratory illness in an analysis published on 19 March. $^{3}$ They said that the benefits of fever should not be overlooked. "Fever is common and is a good prognostic sign in acutely unwell patients with infection, associated with higher rates of survival."

They concluded: "The current evidence does not support routine antipyretic administration to treat fever in acute respiratory infections and covid-19," adding that the rapid and widespread purchase of antipyretic medication over-the-counter has led to temporary shortages."

Day M. Covid-19: ibuprofen should not be used for managing symptoms, say doctors and scientists. BMJ 2020;368:m1086. 10.1136/bmj.m1086 32184201

2 European Medicines Agency. EMA gives advice on the use of non-steroidal anti-inflammatories for COVID-19. March 2020. https://www.ema.europa.eu/en/news/ ema-gives-advice-use-non-steroidal-anti-inflammatories-covid-19

3 Park S, Brassey J, Heneghan C, Mahtani K. Managing fever in adults with possible or confirmed COVID-19 in primary care. CEBM Research. March 20020. https://www.cebm. net/managing-fever-in-adults-with-possible-or-confirmed-covid-19/

Published by the BMJ Publishing Group Limited. For permission to use (where not already granted under a licence) please go to http://group.bmj.com/group/rights-licensing/ permissions 